Check for updates

Cite this: RSC Adv., 2019, 9, 13159

\title{
Development of self-stratified antibacterial polymers via click chemistry
}

\author{
Kaimei Peng, (D) ab Jianqing Hu, (D) *b Xuexin Dai, ${ }^{a}$ Zaibo Yang, ${ }^{a}$ Runping Wang ${ }^{a}$ \\ and Weiping $T^{b}$
}

An azide-modified long perfluorinated tail quaternary ammonium methacrylate compound (M2) was designed and synthesized. The fluorine containing polyurethane (PU-F) with strong antibacterial properties was prepared via click reaction of M2 and a clickable polymer (PU-Al), which exhibited surface segregation. The PU-F film showed a total kill against both Gram-positive Staphylococcus aureus (S. aureus) and Gram-negative Escherichia coli (E. coli) at an M2 content around 1 wt\%. A disk diffusion test confirmed that the ligation efficiency of the antibacterial agents and polymer chains via click chemistry was excellent, and covalent conjugation of the QACs to the polymers prevented leaching.

Received 2nd March 2019

Accepted 24th April 2019

DOI: 10.1039/c9ra01572h

rsc.li/rsc-advances chemicals into the polyurethane composition. ${ }^{25-27}$ QACs grafted antibacterial polymers have been successfully prepared and studied extensively. ${ }^{28}$ The antibacterial mechanism of positively charged QACs is based on a strong electrostatic interaction with negatively charged bacterial cell membrane, and the QACs with long hydrophobic tails ${ }^{29}$ exhibit the excellent antibacterial activity via disrupting the bacterial cell membrane. ${ }^{30}$ For these reasons, QACs grafted polyurethanes have been attracting a lot of interest because of its application in antibacterial

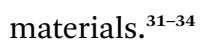

Generally, the antibacterial polymer was evenly distributed in the bulk and on the surface of a material, but antibacterial activity is linked to surface properties. The antibacterial moieties in bulk not only impact material performance but also weaken surface antibacterial activity. ${ }^{35}$ Therefore, the selfstratified polymers are rapidly becoming a major focus of contact-killing materials. Click chemistry, especially the coppercatalyzed azide-alkyne cycloaddition (CuAAC), is an orthogonal and efficient reactor, ${ }^{36,37}$ which is a powerful linkage method for designing antibacterial polymeric materials. Herein, we report the design and synthesis of self-stratified antibacterial polymers (PU-F) containing QACs via click chemistry, and the physiochemical properties and the antibacterial performance of the PU-F were investigated. To analyse the antibacterial activity of PU-F, Gram-negative Escherichia coli (E. coli) and Gram-positive Staphylococcus aureus (S. aureus) were selected as the test organisms because they are very common strains, have faster doubling time and belong to the type strains.

\section{Experimental}

\subsection{Materials}

Monomers including poly(propylene glycol) (PPG, $M_{\mathrm{n}} \sim 1000$ ) and 1,1,1-tris(hydroxymethyl)propane (TMP, 98\%) and 
isophorone diisocyanate (IPDI, 98\%) and 1,6-hexanediol (99\%) were purchased from J\&K chemical Ltd. $N$-Methyldiethanolamine (98\%) and propargyl bromide (98\%) and 2-dimethylaminoethyl chloride hydrochloride (99\%) and sodium azide (99\%) and 1-iodo- $1 H, 1 H, 2 H, 2 H$-perfluorodecane (98\%) were from Aladdin Chemical Ltd. All other materials and solvents were purchased from Sigma. The two bacteria strains used were Gram-negative Escherichia coli (E. coli, ATCC 25922) and Grampositive Staphylococcus aureus (S. aureus, ATCC 29213).

\subsection{Methods}

2.2.1 Synthesis. $\quad N, N$-Bis(2-hydroxyethyl)- $N$-methylprop-2yn-1-aminium bromide (M1) was synthesized by one-step quaternization reaction. Briefly, to a $250 \mathrm{~mL}$ flask charged with $N$ methyldiethanolamine $(10 \mathrm{~g}, 84 \mathrm{mmol})$ and $N, N$-dimethylformamide (DMF, $30 \mathrm{~mL}$ ), propargyl bromide (9.8 g, 84 mmol) was slowly added with stirring at room temperature. Then, stirring was continued for another 24 hours, and a precipitate occurred. The upper clear liquid was removed. The solid was washed three times in acetone, and dried. The product $(18.9 \mathrm{~g})$ was obtained in $95 \%$ yield.

$N$-(2-Azidoethyl)-heptadecafluoro- $N, N$-dimethyldecan-1-aminium iodide (M3) was synthesized according to the following procedure. To a $250 \mathrm{~mL}$ flask charged with $20 \mathrm{~g}$ of 2-dimethylaminoethyl chloride hydrochloride $(139 \mathrm{mmol})$ and $150 \mathrm{~mL}$ of water and $10 \mathrm{~g}$ of sodium azide (154 mmol) and catalytic amount of sodium iodide, the mixture was stirred until fully dissolved. The reaction mixture was heated to $80{ }^{\circ} \mathrm{C}$, and stirring was continued for 36 hours. After being cooled to room temperature, and the mixture was neutralized with sodium carbonate, and the $\mathrm{pH}$ was adjusted to $11.100 \mathrm{~mL}$ of ethyl acetate (EA) was added and subsequently extracted with diethyl ether $(60 \mathrm{~mL} \times 3)$. The combined organic phase was washed by saturated brine $(50 \mathrm{~mL} \times 3)$ and dried with sodium sulfate. The diethyl ether in the mixed solvents was removed at room temperature, and the 2-azido- $N, N$-dimethylethan-1-amine (M2) in ethyl acetate was obtained. $100 \mathrm{~g}$ of 1-iodo- $1 \mathrm{H}, 1 \mathrm{H}, 2 \mathrm{H}, 2 \mathrm{H}$-perfluorodecane was added to the $\mathrm{M} 2$ solution and stirred at $75^{\circ} \mathrm{C}$ for 12 hours, and a yellow precipitate occurred. The upper clear liquid was removed. The solid was washed three times in ethyl acetate, and dried under vacuum at $45^{\circ} \mathrm{C}$ for 2 days. The M3 (57 g) was obtained in $60 \%$ yield.

The clickable alkyne functional polyurethane (PU-Al) was prepared according the following procedure. Briefly, IPDI (60 g, $270 \mathrm{mmol}$ ) and PPG 1000 (55 g, $55 \mathrm{mmol})$ and catalytic amounts of dibutyltin dilaurate (DBTDL) were charged into a $500 \mathrm{~mL}$ dried four-necked flask equipped with a mechanical stirrer, a thermometer, a condenser, and a nitrogen in/outlet. The reaction mixture was heated to $80{ }^{\circ} \mathrm{C}$ for 2 hours and then cooled to 40 room temperature. $280 \mathrm{~mL}$ of DMF and $6 \mathrm{~g}$ of TMP (44 mmol) and a certain amount of 1,6-hexanediol (14 g, 119 $\mathrm{mmol})$ and $\mathrm{M} 1$ ( $2.5 \mathrm{~g}, 11 \mathrm{mmol})$ were added. The reaction was kept at $80{ }^{\circ} \mathrm{C}$ for another 7 hours. The clickable PU-Al in DMF was prepared.

Fluorine-containing polyurethane (PU-F) was synthesized according to the following procedure. $6 \mathrm{~g}$ of PU-Al in DMF solution and $10 \mathrm{~mL}$ of DMF and a certain amount of M3 (8 mg, $15 \mathrm{mg}, 21 \mathrm{mg}$ or $40 \mathrm{mg}$ ) were added into a $100 \mathrm{~mL}$ flask. The mixture was degassed for 20 minutes with nitrogen and $0.2 \mathrm{~g}$ of $\mathrm{CuBr}$ and $0.36 \mathrm{~mL}$ of pentamethyldiethylenetriamine (PMDETA) were added, and stirred at room temperature for 1 hour. The antibacterial polyurethanes PU-F1 (0.40 wt\%), PU-F2 (0.71 wt\%), PU-F3 (1.05 wt\%) and PU-F4 (1.97 wt\%) were prepared.

2.2.2 Spectroscopic characterization. The chemical structures of small molecules and polyurethanes were verified via ${ }^{1} \mathrm{H} /{ }^{13} \mathrm{C}$ NMR spectra (Bruker AVANCE III HD 400 spectrometer) and FT-IR spectrum (Bruker VERTEX 70 in the range of 4000$\left.600 \mathrm{~cm}^{-1}\right)$.

2.2.3 Contact angle. The static contact angles of films were conducted on a JC2000C1 Powereach1 contact angle analyser. The average contact angle was obtained from five tests of each sample.

2.2.4 Gel permeation chromatography (GPC). Molecular weight distribution of the PU-F was studied with gel permeation chromatography (GPC) using a Thermo Scientific chromatograph equipped with a RefractoMax 521 refractive index detector and an isocratic Dionex UltiMate 3000 pump. The

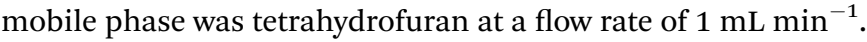
The calibration was performed using polystyrene as standard.

2.2.5 Thermogravimetric analysis (TGA). Thermogravimetric analysis (TGA) of antibacterial polyurethanes was conducted using NETZSCH, TG209 under $\mathrm{N}_{2}$ flow. The samples were heated from room temperature to $600{ }^{\circ} \mathrm{C}$ with a heating rate of $10{ }^{\circ} \mathrm{C} \mathrm{min}^{-1}$.

2.2.6 Differential scanning calorimetry (DSC). DSC tests were conducted using a Netzsch DSC204 differential scanning calorimeter. Polyurethane sample of $5 \mathrm{mg}$ of each material was first heated from room temperature to $150{ }^{\circ} \mathrm{C}$ at a heating rate of $10{ }^{\circ} \mathrm{C} \mathrm{min}^{-1}$ and held in the melting state for 2 minutes to erase the thermal history. This process was followed by quenching to $-80{ }^{\circ} \mathrm{C}$ at $10{ }^{\circ} \mathrm{C} \mathrm{min}^{-1}$ and held for 8 minutes to reach equilibrium. Subsequently, the polymer sample was heated from $-80{ }^{\circ} \mathrm{C}$ to $150{ }^{\circ} \mathrm{C}$ at $10{ }^{\circ} \mathrm{C} \mathrm{min}^{-1}$ again to obtain the thermal property.

2.2.7 X-ray photoelectron spectroscopy (XPS). XPS measurements were performed using an X-ray photoelectron spectrometer (Kratos Axis Ultra DLD, Kratos, UK) with a mono Al-K $\alpha$ excitation source (1486.6 eV) and operated at $15 \mathrm{kV}$ under a current of $5 \mathrm{~mA}$. Polymer samples were placed in an ultrahigh vacuum chamber $\left(5 \times 10^{-9}\right.$ torr $)$ with electron collection by a hemispherical analyzer at the angle of $90^{\circ}$.

2.2.8 Antibacterial activity determination. The antibacterial activity of PU-F was assessed using the antibacterial droptest. $^{38}$ Gram-positive S. aureus (ATCC 29213) or Gram-negative bacterial E. coli (ATCC 25922) was cultured on agar plate at $37^{\circ} \mathrm{C}$ for $24 \mathrm{~h}$, and then a single colony was picked and cultured in culture medium (Mueller-Hinton broth) at $37{ }^{\circ} \mathrm{C}$ for 12 hours. The cell suspension was diluted to $10^{5} \mathrm{CFU} \mathrm{mL}{ }^{-1}$. The samples $(20 \times 20 \times 0.6 \mathrm{~mm})$ were placed into sterile Petri dishes. $100 \mu \mathrm{L}$ of the $10^{5} \mathrm{CFU} \mathrm{mL}^{-1}$ cell suspension was added dropwise onto the surface of each sample, and pure PU was used as a control. The samples were evaluated at $37{ }^{\circ} \mathrm{C}$ for 8 hours. $10 \mathrm{~mL}$ sterile double-distilled water was applied to the sample. $100 \mu \mathrm{L}$ of the suspension in the Petri dish was dispersed on the nutrient agar plate. The plate was incubated 
for 24 hours at $37^{\circ} \mathrm{C}$, and the numbers of colonies on the agar plates were counted. The above experiment was repeated at least three times and the polymer samples were washed with ethanol and sterile double-distilled water and dried at $75{ }^{\circ} \mathrm{C}$ before the experiment.

The disk diffusion of some representative samples was conducted according to the following procedure. The cultured active bacterial suspensions (E. coli) were plated on the solidified agar media. Films $(1 \times 1 \mathrm{~cm})$ were adhered to the medium with their active side on the agar and the plates were incubated at $37^{\circ} \mathrm{C}$ for 24 hours.

\section{Results and discussion}

\subsection{Monomers synthesis}

M1 was synthesized by one-step quaternization reaction in Fig. $1 \mathrm{~A}$ and the structure was confirmed by ${ }^{1} \mathrm{H} /{ }^{13} \mathrm{C}$ NMR and FTIR spectra shown in Fig. 2A and B. ${ }^{1} \mathrm{H}$ NMR peaks of proton at $\delta 2.41 \mathrm{ppm}$ was assigned to alkyne hydrogen $(-\mathrm{C} \equiv \mathrm{CH})$ and the infrared absorption of alkyne group was observed at $2125 \mathrm{~cm}^{-1}$.

The basic strategies employed for the synthesis of M3 are based on the nucleophilic substitution and quaternization reaction. M2 was first synthesized according to the route in Fig. 1B. Its chemical structure was confirmed by ${ }^{1} \mathrm{H}$ NMR result and azide group infrared adsorption at $2104 \mathrm{~cm}^{-1}$ in Fig. 2C and D. The synthesis of M3 involved the reaction of M2 with 1-iodo- $1 H, 1 H, 2 H, 2 H$-perfluorodecane in ethyl acetate (Fig. 1C). ${ }^{1} \mathrm{H} /{ }^{13} \mathrm{C} /{ }^{19} \mathrm{~F}$ NMR and FT-IR spectra confirmed the successful synthesis of M3 (Fig. 2E-H). The advantage of these synthesis is that the operation of experiments is simple and convenient, and the purification of products is without chromatography.

\subsection{Polymer design and synthesis}

The strategy employed in this study is schematically illustrated in Fig. 3. Step-growth polymerization was used to directly prepare clickable polymer (PU-Al) and antibacterial polyurethane (PU-F). Prepolymer was prepared from the reacting between PPG and IPDI. Subsequently, the M1 with alkyne was introduced into the polyurethane chain, and the clickable polyurethane (PU-Al) was synthesized. The chemical structure of PU-Al was investigated via ${ }^{1} \mathrm{H}$ NMR in Fig. 4. Compared with pure PU, several new peaks appeared at $\delta 3.18, \delta 3.74, \delta 4.08$, and $\delta 4.51$, which could be assigned to the chemical shifts of the protons on the $-\mathrm{N}^{+}\left(\mathrm{CH}_{3}\right)^{-},-\mathrm{N}^{+} \mathrm{CH}_{2}-\mathrm{CH}_{2}-\mathrm{OH},-\mathrm{N}^{+} \mathrm{CH}_{2}^{-}$, and $-\mathrm{C} \equiv \mathrm{CH}$.

\subsection{Thermal properties}

DSC and TGA were used to assess the thermal properties of PU$\mathrm{Al}$ and PU-F. As shown in Fig. 6, compared with PU, the glass transition temperature $\left(T_{\mathrm{g}}\right)$ of clickable polyurethane PU-Al increased by $5.7{ }^{\circ} \mathrm{C}$ when the percent content of clickable monomer (M1) is $1.86 \%$, which may be caused by the introduction of alkyne side chain. The glass transition temperatures $\left(T_{\mathrm{g}} \mathrm{S}\right)$ for PU-F 2 and PU-F 3 were 30.2 and $32.3{ }^{\circ} \mathrm{C}$, respectively. The $T_{\mathrm{g}} \mathrm{S}$ of PU-F were larger than PU-Al, and they increased with the proceeding of click reaction, which was attributed to the formation of rigid triazole rings by CuAAC click reaction. ${ }^{23,39}$

TGA results provide the information, including volatile content and decomposition temperature $\left(T_{\mathrm{d}}\right)$. The degradation of polyurethane is a step-by-step process. ${ }^{\mathbf{4 0 , 4 1}}$ In the first stage, the PU polymer chains were decomposed due to the $\mathrm{C}-\mathrm{NH}$ bond breaking. ${ }^{42}$ The PU, PU-Al and PU-F started to decompose at $200{ }^{\circ} \mathrm{C}$ as shown in Fig. 7. The first peak of decomposition rate occurred as the temperature rose about $326^{\circ} \mathrm{C}$. At this point, the hard segments of polyurethanes were almost degraded because of the breaking of urethane bonds. In the second stage, the ether bond (C-O) began to break down, and then the soft segments were decomposed. At the second peak, the temperature of PU-Fs were larger than that of PU and PU-Al because the formation of the thermal stable triazole ring. ${ }^{43}$ The results is in accordance with the increase of $T_{\mathrm{g}}$ of PU-F in comparison to PU. Hence, the CuAAC reaction combine providing the efficient method for fabricating functional polymer and improving the thermal stability.

\subsection{XPS analysis and contact angle measurements}

XPS was used to investigate the film surface chemical compositions, and the fluorine over total carbon $(\mathrm{F} / \mathrm{C})$ ratio was measured. As can be seen in Fig. 8, the C1s peak for the PU-F 3 (1.05 wt\%) film was curve fitted into four peaks (Fig. 8B), and these peaks are assigned to different carbon environments: $\mathrm{C}-$ $\mathrm{C} / \mathrm{C}-\mathrm{H}\left(\sim 285 \mathrm{eV}\right.$; its peak area was $\left.\mathrm{A}_{1}\right), \mathrm{C}=\mathrm{O}\left(\sim 289 \mathrm{eV} ; \mathrm{A}_{2}\right), \mathrm{CF}_{2}$

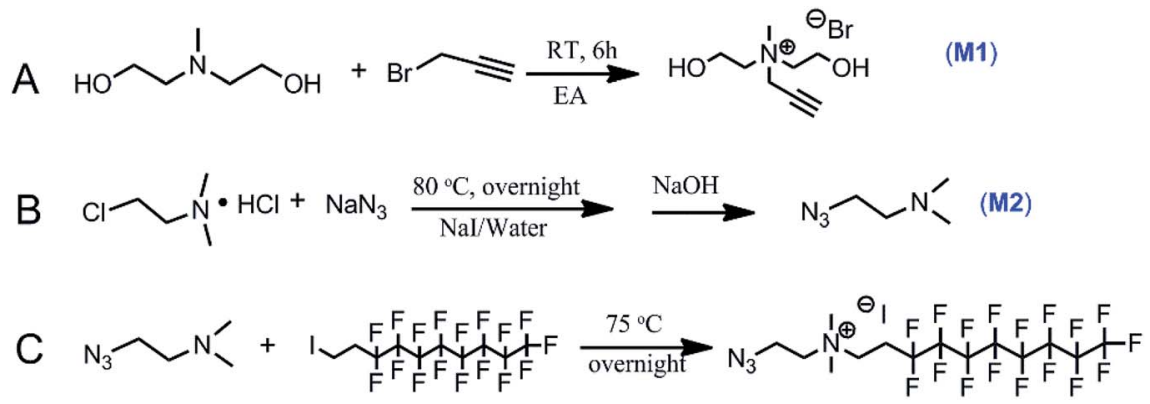

(M3)

Fig. 1 Synthetic routes for the monomers. 

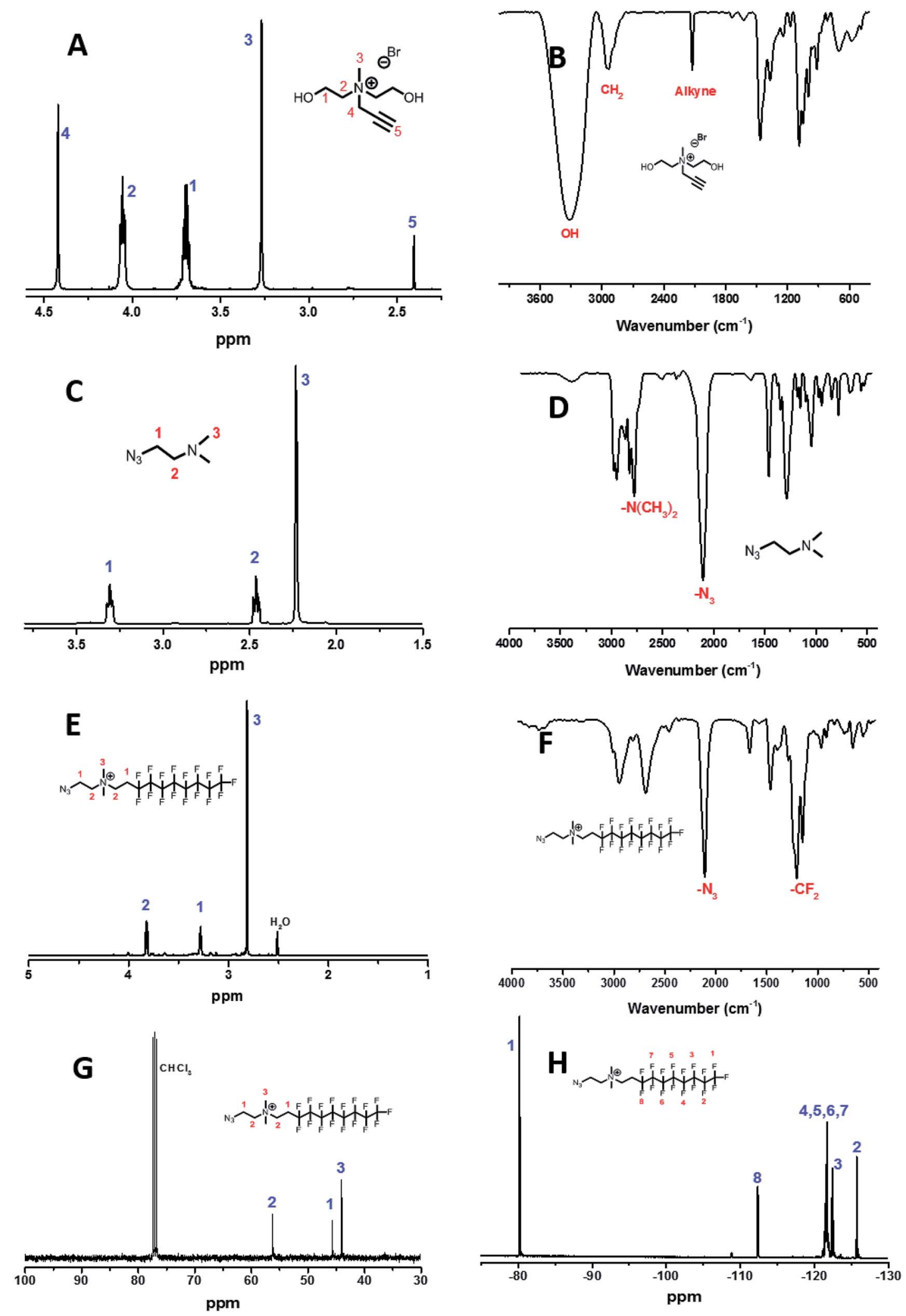

Fig. $2{ }^{1} \mathrm{H}$ NMR and FT-IR spectra of $M 1(A$ and $B), M 2(C$ and $D), M 3(E$ and $F)$ and ${ }^{13} C /{ }^{19} F$ NMR spectra of $M 3(G$ and $H)$. 


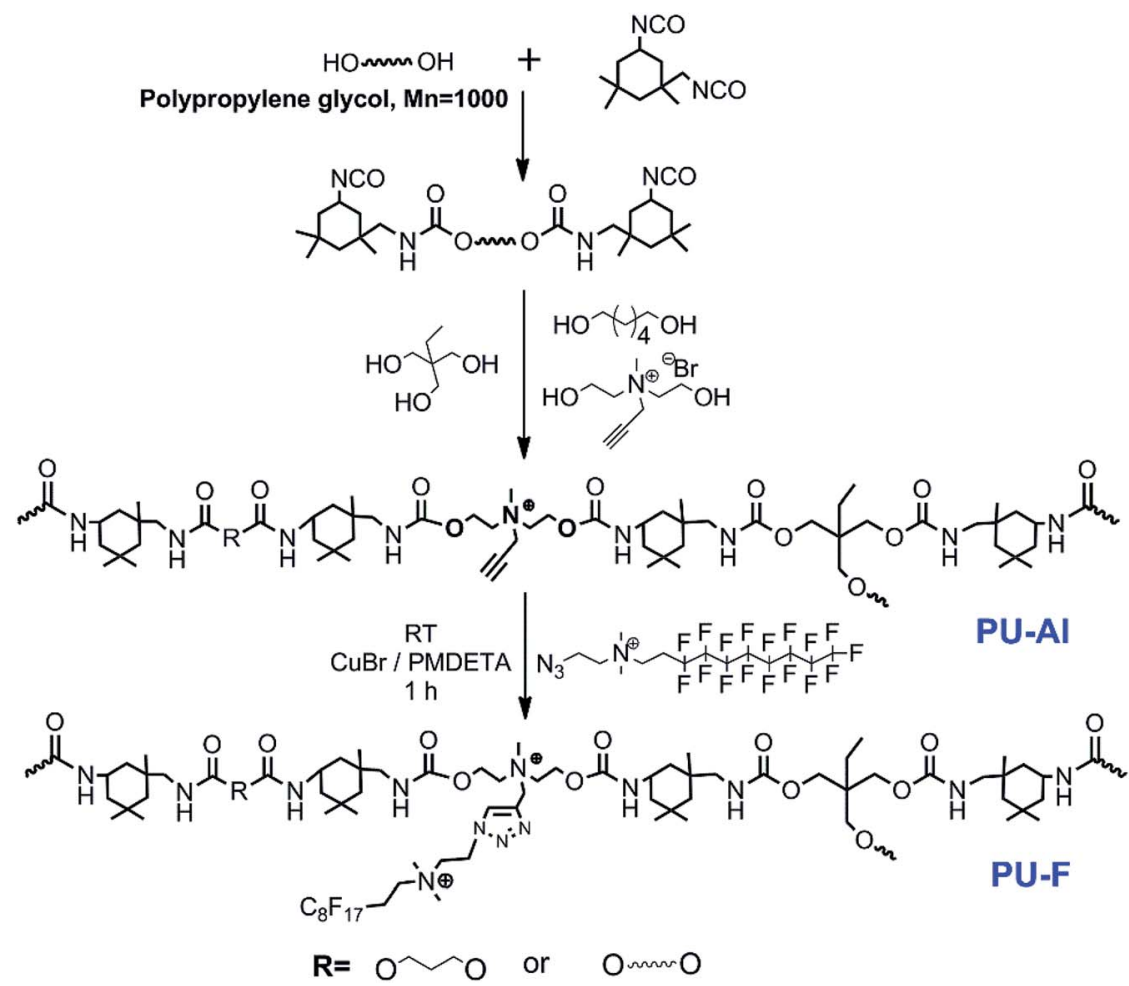

Fig. 3 Two synthetic strategies for the polymers. The synthesis of fluorine-containing polyurethane (PU-F) involved the reaction of PU-Al with compound M3 via click chemistry. The FT-IR spectra provided the evidence of the successful synthesis of PU-F. Fig. 5 shows the successful transformation of PU-Al into PU-F4 by monitoring the disappearance of an azide peak at $2104 \mathrm{~cm}^{-1}$ after click reaction. The PU-F 3 was determined by GPC analysis. The number average molecular weights $\left(M_{n}\right)$ and the polydispersity indexes (PDI) of the PU-F 3 was $1.019 \times 10^{4} \mathrm{~g}$ $\mathrm{mol}^{-1}$ and 1.786, respectively.

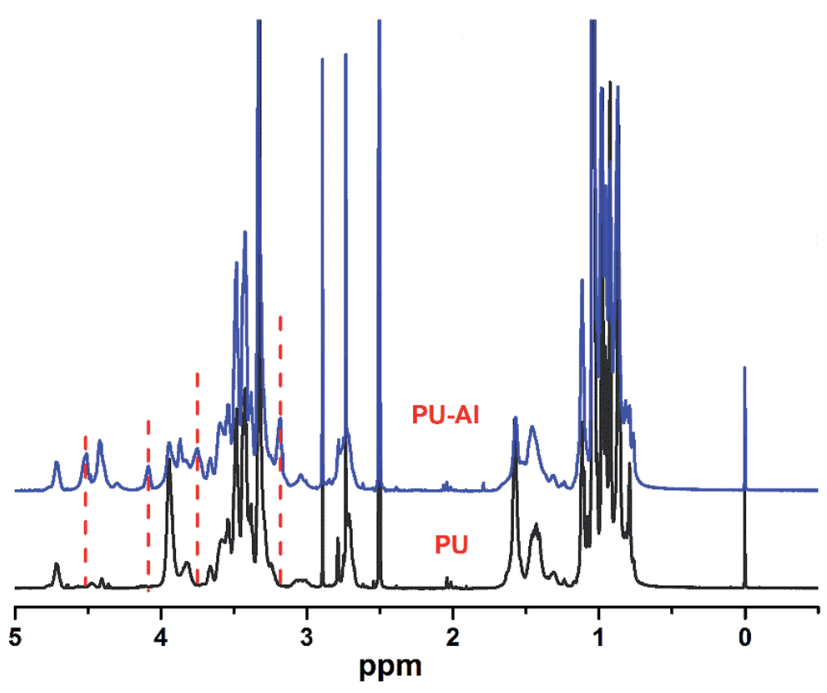

Fig. $4{ }^{1}$ HNMR spectra of non-clickable polyurethane (PU), clickable polyurethane with side-chain alkyne (PU-Al).

$\left(\sim 292 \mathrm{eV} ; \mathrm{A}_{3}\right)$, and $\mathrm{CF}_{3}\left(\sim 294 \mathrm{eV} ; \mathrm{A}_{4}\right)$. The $\mathrm{F} / \mathrm{C}$ ratio was estimated according to eqn (1)..$^{35,44}$

$$
\frac{\mathrm{F}}{\mathrm{C}}=\frac{2 \mathrm{~A}_{3}+3 \mathrm{~A}_{4}}{\sum_{i=1}^{4} \mathrm{~A}_{i}}
$$

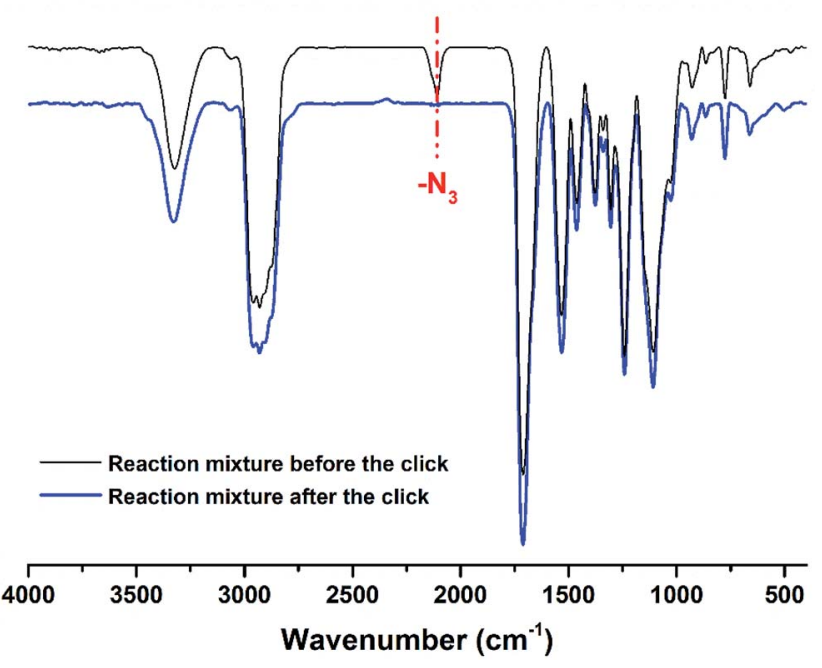

Fig. 5 The FT-IR spectra of reaction mixture containing the PU-Al and M3 before or after the click reaction.

In Fig. 8B, F/C ratio for the PU-F 3 film surface was 0.116, and that for the estimated bulk average was about 0.0035 . Obviously, fluorine enrichment occurred at the film surface, and the surface enrichment factor was 33 . The XPS results showed that PU-F film resulted in a much higher $\mathrm{F} / \mathrm{C}$ ratio than its bulk value, which was in line with static contact angle of PU-Al $\left(69^{\circ}\right)$, PU-F $2\left(83^{\circ}\right)$, PU-F $3\left(101^{\circ}\right)$, and PU-F $4\left(104^{\circ}\right)$. 


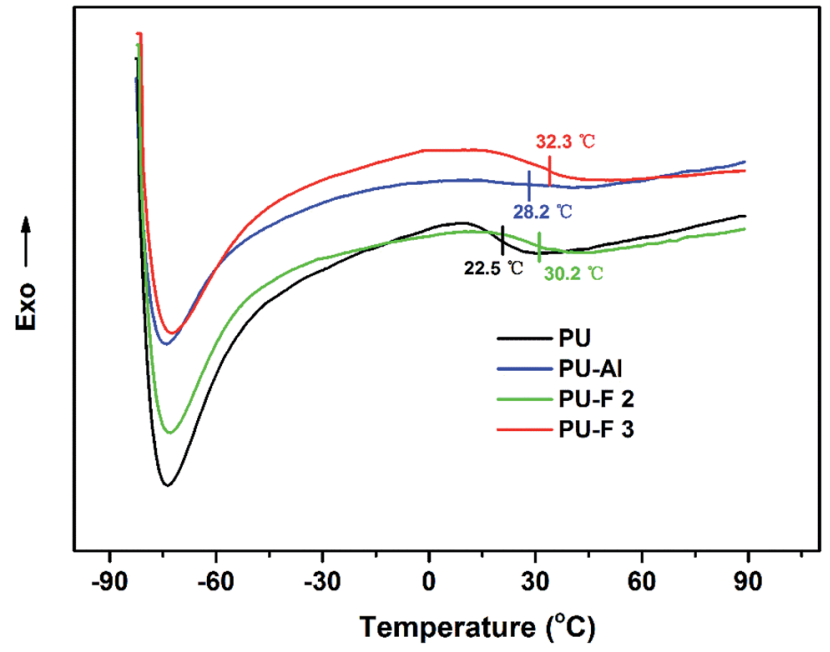

Fig. 6 DSC curves of PU, PU-Al (wt\% = 1.86\%), PU-F $2(w t \%=0.71 \%)$ and PU-F 3 (wt\% = 1.05\%).
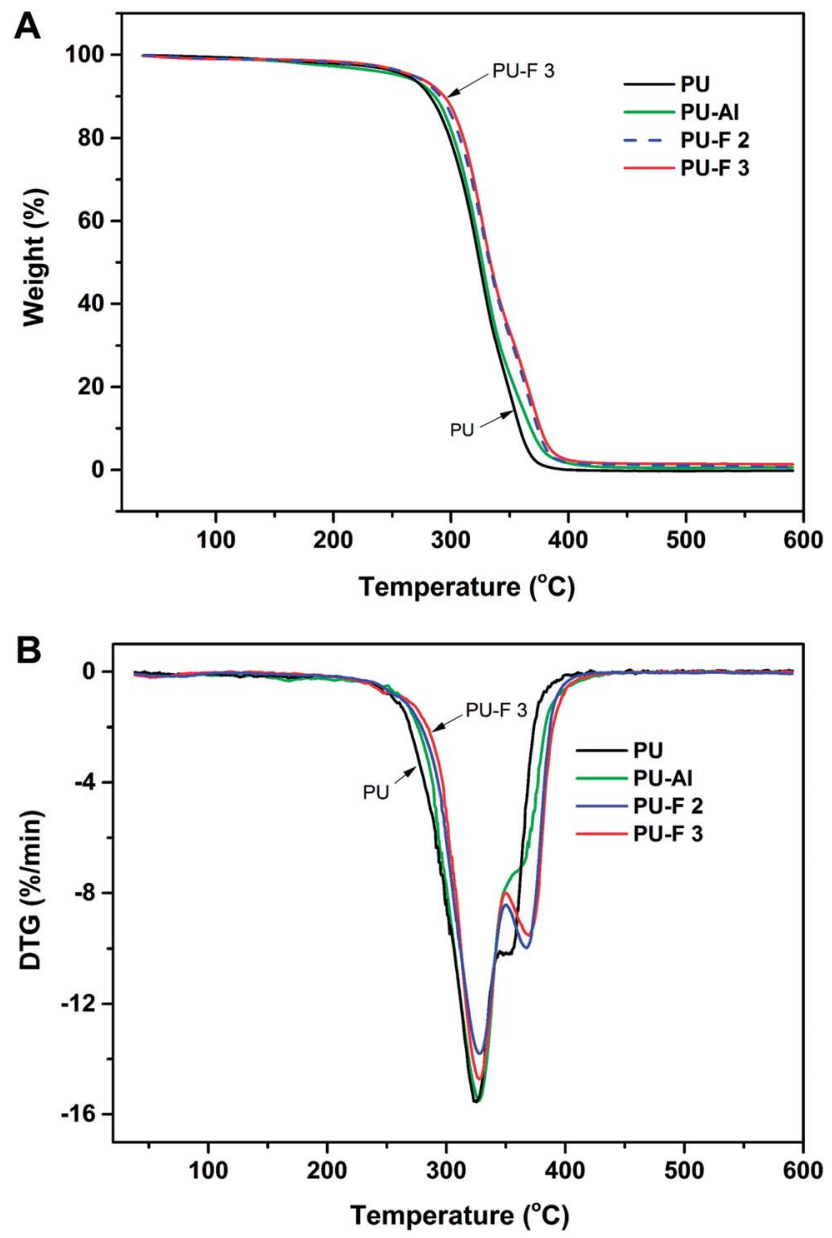

Fig. 7 TGA (A) and DTG (B) curves of PU, PU-Al (wt\% =1.86\%), PU-F 2 $(w t \%=0.71 \%)$ and PU-F $3(w t \%=1.05 \%)$.

\subsection{Antibacterial activity}

Antibacterial activities of the films were monitored by using the Gram-positive Staphylococcus aureus and Gram-negative Escherichia coli, through the antibacterial "drop test"
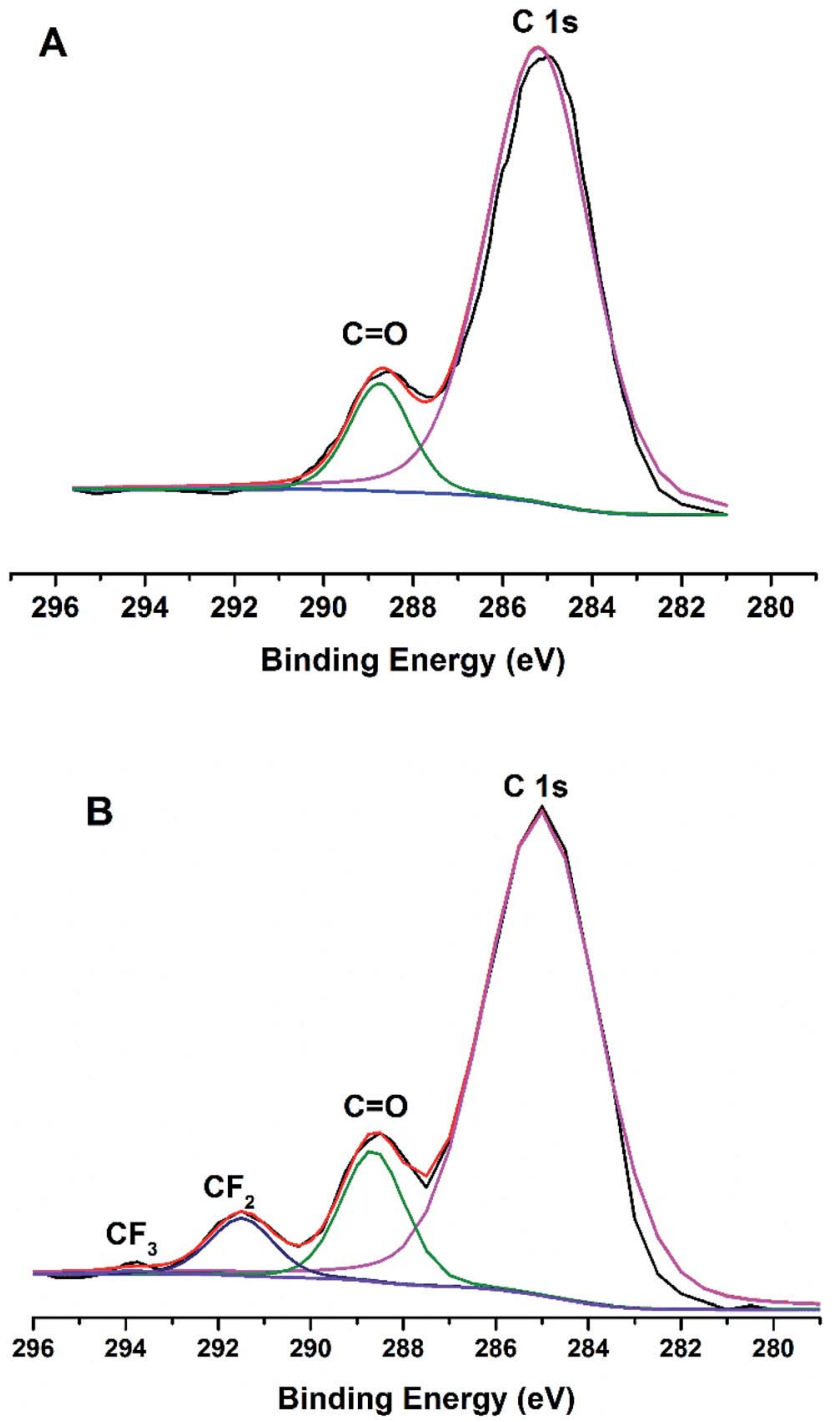

Fig. 8 XPS C1s signals at a takeoff angle of $90^{\circ} \mathrm{C}$; (A) PU and (B) PU-F 3 (1.05 wt\%)

method. ${ }^{38}$ PU was used as control, and the percentage of bacteria kill was evaluated via eqn (2) as below:

$$
\text { Percentage of bacteria kill }=\frac{A-B}{A} \times 100 \%
$$

Here $A=$ CFUs after control (PU) surface contact, $B=$ CFUs after PU-Al or PU-F surface contact.

Notably, all PU-F samples, especially PU-F 2 and 3, exhibited strong antibacterial behavior against both $S$. aureus and E. coli. As shown in Fig. 9 and 10, the PU-F 2 (0.7 wt\%) film surface exhibited bacteria kill rate about $86 \%$ and $95 \%$ against $S$. aureus and $E$. coli, respectively. $1.0 \%$ fluorine-containing monomer (M2) content in polymer is enough to inhibit $S$. aureus or E. coli. Due to its hydrophobic long perfluoroalkyl chains, M2 was an efficiently diffusing QAC towards the material surface and resulted in the increase of positive charge density on the surface, which is consistent with the mechanism that the cationic charge density at a surface is the key determining factor 

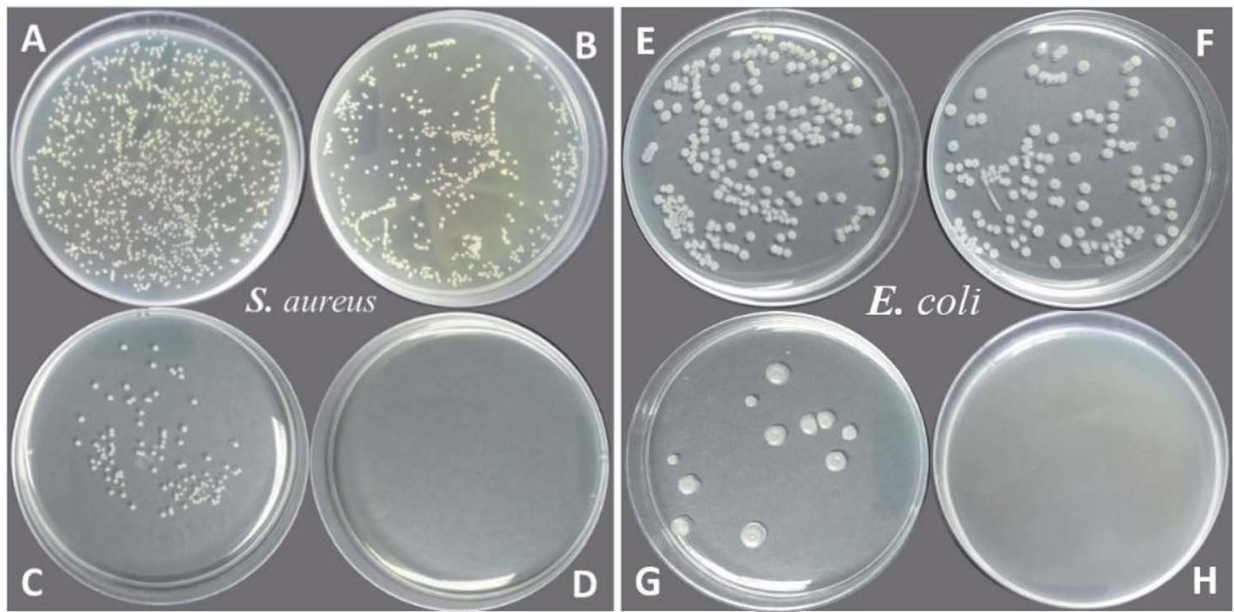

Fig. 9 Antibacterial activity of PU (blank, A and E), PU-Al (B and F), PU-F 2 (C and G), PU-F 3 (D and H) for Staphylococcus aureus and Escherichia coli, respectively.

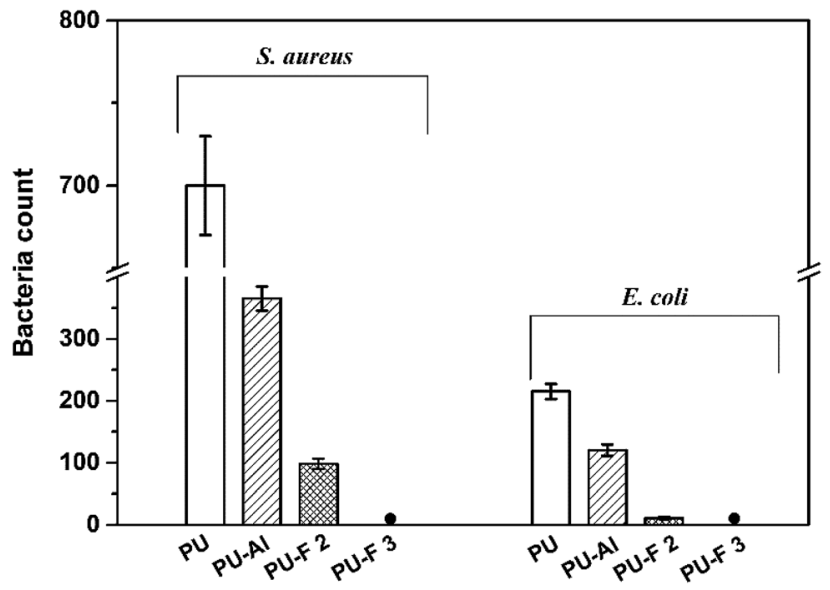

Fig. 10 The comparison of antibacterial capability of PU-Al, PU-F 2 and PU-F 3.

in the antibacterial activity. ${ }^{45,46}$ Interestingly, clickable polyurethane PU-Al (1.86 wt\%) exhibited antibacterial properties, and its surface showed a bacteria kill rate about $47 \%$ and $44 \%$ against $S$. aureus and $E$. coli, respectively. This may be ascribed to the QAC structures on the main chains.

Free QACs are effective antibacterial agent, and they will be unfriendly to the environment and trigger antibiotic-resistance. To confirm that the QACs were covalently bonded with the polymer chains via click chemistry, the disk diffusion of PU-F was carried out on E. coli. As shown in Fig. 11, there was no leaching of free QACs and no zones of inhibition around PU-F film, which is proof that PU-F is a non-leaching contact-killing polymer and the CuAAC is an efficient tool to fabricate the antibacterial polymer. In sum, the antibacterial mechanism of PU-Fs are similar to that of QACs, but the antibacterial moieties in bulk not only impact material performance but also weaken surface antibacterial activity. Therefore, the self-stratified polymers (PU-Fs) were fabricated by introducing the fluorines.

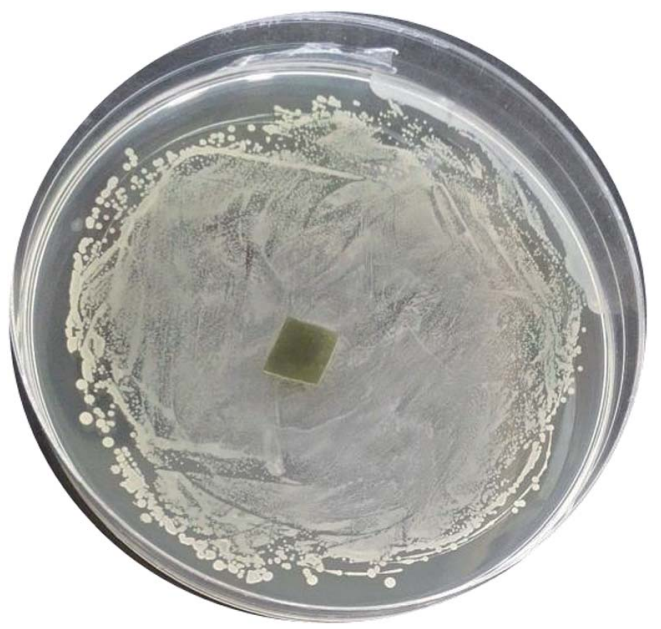

Fig. 11 Disk diffusion of antibacterial polyurethane (PU-F) for Escherichia coli.

\section{Conclusions}

A self-stratified antibacterial polymer (PU-F) was developed via click reaction between clickable polyurethane and azidemodified long perfluorinated tail QAC (M2). The click chemistry is efficient method for the connection of antibacterial functional blocks, and no antibacterial ingredient leaching was observed. The prepared self-stratified PU-F films exhibited strong antibacterial activities against both Gram-positive $S$. aureus and Gram-negative $E$. coli bacteria at low concentrations due to the surface enrichment of the quaternary ammonium moieties. Moreover, the clickable polyurethane (PU-Al) showed the antibacterial activity because of the positive charges on the polymer chains. Hence, we conclude that the click chemistry is the optimal approach for preparing the functional surface materials. 


\section{Conflicts of interest}

There are no conflicts to declare.

\section{Acknowledgements}

This work was supported by the Aleo BME, Inc. and the Department of Education of Guizhou Province (KY[2018]425), Special Fund of Qiannan Normal University for Nationalities (QNSY2018BS013, QNSYTD2017002) and Technology Bureau of Qiannan.

\section{References}

1 M. Cloutier, D. Mantovani and F. Rosei, Trends Biotechnol., 2015, 33, 637-652.

2 S. S. Magill, J. R. Edwards, W. Bamberg, Z. G. Beldavs, G. Dumyati, M. A. Kainer, R. Lynfield, M. Maloney, L. McAllister-Hollod, J. Nadle, S. M. Ray, D. L. Thompson, L. E. Wilson and S. K. Fridkin, N. Engl. J. Med., 2014, 370, 1198-1208.

3 A. Y. Peleg and D. C. Hooper, N. Engl. J. Med., 2010, 362, 1804-1813.

4 K. Rutledge-Taylor, A. Matlow, D. Gravel, J. Embree, N. Le Saux, L. Johnston, K. Suh, J. Embil, E. Henderson, M. John, V. Roth, A. Wong, J. Shurgold and G. Taylor, Am. J. Infect. Control, 2012, 40, 491-496.

5 P. Zarb, B. Coignard, J. Griskeviciene, A. Muller, V. Vankerckhoven, K. Weist, M. M. Goossens, S. Vaerenberg, S. Hopkins, B. Catry, D. L. Monnet, H. Goossens and C. Suetens, Euro Surveill., 2012, 17, 20316.

6 B. Allegranzi, S. B. Nejad, C. Combescure, W. Graafmans, H. Attar, L. Donaldson and D. Pittet, Lancet, 2011, 377, 228-241.

7 V. B. Schwartz, F. Thétiot, S. Ritz, S. Pütz, L. Choritz, A. Lappas, R. Förch, K. Landfester and U. Jonas, Adv. Funct. Mater., 2012, 22, 2376-2386.

8 L. A. T. W. Asri, M. Crismaru, S. Roest, Y. Chen, O. Ivashenko, P. Rudolf, J. C. Tiller, H. C. van der Mei, T. J. A. Loontjens and H. J. Busscher, Adv. Funct. Mater., 2014, 24, 346-355.

9 J. Zhao, L. Song, Q. Shi, S. Luan and J. Yin, ACS Appl. Mater. Interfaces, 2013, 5, 5260-5268.

10 M. Lejars, A. Margaillan and C. Bressy, Chem. Rev., 2012, 112, 4347-4390.

11 L. Massi, F. Guittard, R. Levy, Y. Duccini and S. Geribaldi, Eur. J. Med. Chem., 2003, 38, 519-523.

12 S. Ye, P. Majumdar, B. Chisholm, S. Stafslien and Z. Chen, Langmuir, 2010, 26, 16455-16462.

13 M. Harney, R. Pant, P. Fulmer and J. Wynne, ACS Appl. Mater. Interfaces, 2009, 1, 39-41.

14 A. Kumar, P. Vemula, P. Ajayan and G. John, Nat. Mater., 2008, 7, 236-241.

15 Z. Shu, Y. Zhang, Q. Yang and H. Yang, Nanoscale Res. Lett., 2017, 12, 135.

16 A. Ghavaminejad, C. H. Park and c. s. Kim, Biomacromolecules, 2016, 17, 1213-1223.
17 A. Rai, A. Prabhune and C. Perry, J. Mater. Chem., 2010, 20, 6789-6798.

18 J.-Y. Kim, J.-H. Kim, G. Ahn, S.-H. An, R.-H. Ryu, J.-S. Kim, Y. Cheol Kim, J.-H. Shim, S.-Y. Kim and W.-S. Yun, Mater. Lett., 2018, 212, 263-266.

19 S. D. Worley, R. Wu, F. Li, J. Kim, C. I. Wei, J. F. Williams, J. R. Owens, J. D. Wander, A. M. Bargmeyer and M. E. Shirtliff, Surf. Coat. Int., Part B, 2003, 86, 273-277.

20 S. Farah, O. Aviv, M. Daif, K. Reddy Kunduru, N. Laout, S. Ratner, N. Beyth and A. J. Domb, J. Polym. Sci., Part A: Polym. Chem., 2016, 54, 596-610.

21 M. Yagci, S. Bolca, J. Heuts, W. Ming and G. With, Prog. Org. Coat., 2011, 72, 343-347.

22 J. Yatvin, J. Gao and J. Locklin, Chem. Commun., 2014, 50, 9433-9442.

23 K. Peng, T. Zou, W. Ding, R. Wang, J. Guo, J. J. Round, W. Tu, C. Liu and J. Hu, RSC Adv., 2017, 7, 24903-24913.

24 S. Heydarifard, Y. Pan, H. Xiao, M. M. Nazhad and O. Shipin, Carbohydr. Polym., 2017, 163, 146-152.

25 E. G. Rightor, S. G. Urquhart, A. P. Hitchcock, H. Ade, A. P. Smith, G. E. Mitchell, R. D. Priester, A. Aneja, G. Appel, G. Wilkes and W. E. Lidy, Macromolecules, 2002, 35, 5873-5882.

26 A. Chortos, G. I. Koleilat, R. Pfattner, D. Kong, P. Lin, R. Nur, T. Lei, H. Wang, N. Liu, Y. C. Lai, M. G. Kim, J. W. Chung, S. Lee and Z. Bao, Adv. Mater., 2016, 28, 4441-4448.

27 E. Delebecq, J. P. Pascault, B. Boutevin and F. Ganachaud, Chem. Rev., 2013, 113, 80-118.

28 H. Bakhshi and S. Agarwal, Polym. Chem., 2016, 7, 53225330.

29 J. Pant, J. Gao, M. J. Goudie, S. P. Hopkins, J. Locklin and H. Handa, Acta Biomater., 2017, 58, 421-431.

30 M. B. Yagci, S. Bolca, J. P. A. Heuts, W. Ming and G. de With, Prog. Org. Coat., 2011, 72, 305-314.

31 E. Udabe, M. Isik, H. Sardon, L. Irusta, M. Salsamendi, Z. Sun, Z. Zheng, F. Yan and D. Mecerreyes, J. Appl. Polym. Sci., 2017, 134, 45473.

32 S. Du, Y. Wang, C. Zhang, X. Deng, X. Luo, Y. Fu and Y. Liu, J. Mater. Sci., 2018, 53, 215-229.

33 Y. Wang, J. Zhao, L. Sha, Y. Zhu and X. Li, J. Mater. Sci., 2018, 53, 1610-1622.

34 W. J. Yang, K.-G. Neoh, E.-T. Kang, S. L.-M. Teo and D. Rittschof, Prog. Polym. Sci., 2014, 39, 1017-1042.

35 J. Zhao, W. Millians, S. Tang, T. Wu, L. Zhu and W. Ming, ACS Appl. Mater. Interfaces, 2015, 7, 18467-18472.

36 J. M. Spruell, M. Wolffs, F. A. Leibfarth, B. C. Stahl, J. Heo, L. A. Connal, J. Hu and C. J. Hawker, J. Am. Chem. Soc., 2011, 133, 16698-16706.

37 K. Brooks, J. Yatvin, C. D. McNitt, R. A. Reese, C. Jung, V. V. Popik and J. Locklin, Langmuir, 2016, 32, 6600-6605.

38 J. J. Lin, W. C. Lin, S. D. Li, C. Y. Lin and S. H. Hsu, ACS Appl. Mater. Interfaces, 2013, 5, 433-443.

39 J. Guo, Z. Xie, R. T. Tran, D. Xie, D. Jin, X. Bai and J. Yang, Adv. Mater., 2014, 26, 1906-1911.

40 K. Pielichowska, J. Bieda and P. Szatkowski, Renewable Energy, 2016, 91, 456-465. 
41 L. Shufen, J. Zhi, Y. Kaijun, Y. Shuqin and W. K. Chow, Polym.-Plast. Technol. Eng., 2006, 45, 95-108.

42 D. K. Chattopadhyay and D. C. Webster, Prog. Polym. Sci., 2009, 34, 1068-1133.

43 K. G. Priyanka, A. K. Mishra, S. Kantheti, R. Narayan and K. V. S. N. Raju, J. Appl. Polym. Sci., 2012, 126, 2024-2034.
44 T. Dikic, W. Ming, P. Thune, R. van Benthem and G. de With, J. Polym. Sci., Part A: Polym. Chem., 2008, 46, 218-227.

45 J. Y. Huang, H. Murata, R. R. Koepsel, A. J. Russell and K. Matyjaszewski, Biomacromolecules, 2007, 8, 1396-1399.

46 H. Murata, R. R. Koepsel, K. Matyjaszewski and A. J. Russell, Biomaterials, 2007, 28, 4870-4879. 